\title{
JURNAL EKONOMI \\ EFEKTIF

\section{HUBUNGAN GAYA KEPEMIMPINAN DAN PENEMPATAN PEGAWAI DENGAN PRODUKTIVITAS KERJA PEGAWAI PADA DINAS KOPERASI DAN UKM DI KOTA TANGERANG SELATAN}

\author{
Hendy Surahman \\ hendysurahman@gmail.com
}

\begin{abstract}
ABSTRAK
Salah satu metode menghitung besarnya pengaruh produktivitas kerja adalah dengan menilai bagaimana hubungan gaya kepemimpinan dan Penempatan Kerja. Gaya kemimpinan dan penempatan kerja berperan dalam meningkatkan produktivitas kerja pegawai, dikarenakan pengaruh seorang pemimpin dan penempatan kerja di dalam mengoperasikan organisasi dengan individu yang berbeda-beda, maka seorang pemimpin harus benar-benar berkualitas agar ia dapat memimpin bawahannya dan menempatkan bawahannya dengan tepat dan baik sehingga produktivitas dan tujuan organisasi dapat dicapai secara efektif dan efisien di Dinas Koperasi dan UKM Kota Tangerang Selatan.

Nilai $r$ sebesar 0,792 menunjukan hubungan yang sangat kuat dan positif antara gaya kepemimpinan dan produktivitas kerja yang berarti jika pelaksanaan gaya kepemimpinan dilakukan dengan baik dan tepat maka akan meningkatkan produktivitas kerja pegawai. Nilai $\mathrm{r}$ sebesar 0,790 menunjukan hubungan yang kuat dan positif antara Penempatan dan Produktivitas Kerja yang berarti jika Penempatan pegawai dilaksanakan dengan baik dan tepat maka akan meningkatkan Produktivitas Kerja pegawai.

Nilai r sebesar 0,872 menunjukan hubungan yang sangat kuat dan positif antara gaya kepemimpinan, penempatan pegawai dan produktivitas kerja. Berdasarkan pengujian Hipotesis diperoleh nilai F hitung > F tabel $(84,199>3,17)$, maka Ho ditolak dan Ha diterima, yang berarti gaya kepemimpinan dan penempatan mempunyai pengaruh yang signifikan terhadap produktivitas kerja pada Dinas Koperasi dan UKM Kota Tangerang Selatan.
\end{abstract}

\section{Kata Kunci: Gaya Kepemimpinan, Penempatan Pegawai dan Produktivitas Pegawai}

\section{ABSTRACT}

One method of calculating the magnitude of the effect of work productivity is to assess how the relationship between leadership style and work placement. Leadership style and work placement play a role in increasing employee work productivity, due to the influence of a leader and work placement in operating an organization with different individuals, then a leader must be truly qualified so that he can lead his subordinates and place his subordinates appropriately and well so that productivity and organizational goals can be achieved effectively and efficiently in the Office of Cooperatives and SMEs in South Tangerang City.

$R$ value of 0.792 indicates a very strong and positive relationship between leadership style and work productivity, which means that if the implementation of leadership style is done properly and correctly, it will increase employee productivity. $R$ value of 0.790 indicates a 
strong and positive relationship between Placement and Work Productivity, which means that if the Placement of employees is carried out properly and correctly, it will increase Employee Productivity.

$R$ value of 0.872 indicates a very strong and positive relationship between leadership style, employee placement and work productivity. Based on the Hypothesis testing obtained values F count> F table (84.199> 3.17), then Ho is rejected and Ha is accepted, which means leadership style and placement have a significant influence on work productivity at the Office of Cooperatives and SMEs in South Tangerang City.

\section{Keywords: Leadership Style, Employee Placement and Employee Productivity}

\section{PENDAHULUAN}

Saat ini pertumbuhan dan perkembangan perekonomian di Indonesia semakin pesat sehingga persaingan diantara para pengusaha kecil menengah juga semakin ketat. Masingmasing berusaha membenahi usahanya dalam segala aspek mulai dari produksi, pemasaran, keuangan, personalia dan juga pembenahan di dalam organisasi. Oleh sebab itu diharapkan pengusaha dapat memenuhi tuntutan untuk beroperasi seefektif dan seefisien mungkin juga dapat tetap bertahan menghadapi para pesaingnya.

Melihat betapa pentingnya pengaruh seorang pemimpin dan penempatan kerja di dalam mengoperasikan organisasi dengan individu yang berbeda-beda, maka seorang pemimpin harus benar-benar berkualitas agar ia dapat memimpin bawahannya dan menempatkan bawahannya dengan tepat dan baik sehingga produktivitas dan tujuan perusahaan dapat dicapai secara efektif dan efisien.

\section{METODE PENELITIAN}

\section{A. Desain Penelitian}

Metode penelitian yang digunakan adalah metode penelitian kuantitatif dengan survey non kausal dimana latar belakang masalahnya sudah jelas beberapa variabel yang akan diteliti yaitu variabel bebas adalah gaya kepemimpinan dan penempatan kerja. Sedangkan variabel terikatnya adalah produktivitas kerja.

\section{B. Populasi dan Sampling}

Ukuran sampel yang digunakan oleh penulis ditentukan berdasarkan pertimbangan menggunakan rumus slovin sebagaimana yang dikutip oleh Husein Umar (2003:108) yaitu:

$$
n=\frac{N}{1+N e^{2}}
$$

Jika diketahui populasi pegawai Dinas Koperasi dan UKM Kota Tangerang Selatan \pm 128 pegawai maka ukuran kelayakan sampel yang digunakan adalah :

128

$$
\begin{aligned}
n= & \\
& 1+128(0,1)^{2} \\
= & 56,14=56
\end{aligned}
$$

berdasarkan perhitungan diatas maka jumlah responden yang dilibatkan dalam penelitian ini adalah 56 responde 


\section{Metode Analisis Data}

Proses pengolahan dan analisa data untuk menguji hipotesis dilakukan dengan prosedur sebagai berikut :

1. Mencari keeratan hubungan antar variabel

Untuk mengetahui kereratan hubungan antar variabel yang diteliti, penulis menggunakan analisis Koefisien Korelasi dengan menggunakan rumus Pearson Product Moment yang dikutip oleh Sugiyono (2005:213) sebagai berikut :

$$
n \Sigma X Y-\Sigma X \Sigma Y
$$

$$
\mathrm{r}=\frac{}{\sqrt{ }\left(n \Sigma X^{2}-(\Sigma X)^{2}\right)\left(n \Sigma Y^{2}-(\Sigma Y)^{2}\right)}
$$

Adapun rumus koefisien Korelasi Berganda menurut Sugiyono (2005:216) adalah :

$$
R_{y . x 1 \times 2}=\sqrt{\frac{r_{y x 1}^{2}+r_{y x 2}^{2}-2 r_{y x 1} r_{y x 2} r_{x 1 \times 2}}{1-r^{2}{ }_{x 1 \times 2}}}
$$

Sedangkan untuk mencari seberapa besar variabel independent mempengaruhi variabel dependennya maka digunakan analisis koefisien determinasi sebagai berikut : $\mathrm{Kd} \quad=\mathrm{r}^{2} \times 100 \%$

2. Menentukan Persamaan Regresi Berganda

Bentuk persamaan regresi dengan dua variabel independent adalah :

$Y=a+b_{1} X_{1}+b_{2} X_{2}$

3. Pengujian asumsi klasik model regresi

a. Uji Normalitas

b. Uji Multikolinieritas

c. Uji Heterokedastisitas

d. Uji Autokorelasi

Nilai Durbin-Watson (DW) dicari dengan menggunakan rumus :

$\mathrm{n}$

$$
\sum\left(\mathrm{e}_{\mathrm{t}}-\mathrm{e}_{\mathrm{t}-1}\right)^{2}
$$

$$
\mathrm{t}=2
$$

$\mathrm{DW}=$

$$
\begin{array}{ll}
\mathrm{n} & \\
\Sigma & \mathrm{e}_{\mathrm{t}}^{2}
\end{array}
$$$$
\mathrm{t}=1
$$

\section{Rancangan Uji Hipotesis}

Suatu koefisien korelasi harus mempunyai nilai yang berarti (signifikan) untuk menguji kebenaran koefisien korelasi, langkah-langkah yang ditempuh adalah :

1. Hipotesis Statistik

Ho ; $\beta=0$, artinnya tidak ada pengaruh antara Gaya Kepemimpinan dan Penempatan pegawai terhadap Produktivitas kerja.

$\mathrm{Ha} ; \beta \neq 0, \quad$ terdapat pengaruh antara Gaya Kepemimpinan dan penempatan pegawai terhadap produktivitas kerja. 
2. Perhitungan F (obs) dan F (tab)

$$
F_{(o b s)}=\frac{M S R}{M S E}=\frac{S S R / k}{S S E /(n-k)}
$$

3. Kriteria penerimaan hipotesis

a. $\mathrm{F}(\mathrm{obs})<\mathrm{F}(\mathrm{tab})$ : Ho diterima artinya tidak ada pengaruh antar variabel.

b. F (obs) $\geq F$ (tab) : Ho ditolak artinya ada pengaruh antar variabel.

\section{HASIL PENELITIAN DAN PEMBAHASAN}

\section{A. Pengujian Asumsi Klasik Model Regresi}

Model Regresi yang diperoleh dari metode kuadrat terkecil (Ordinary Least Square /OLS) merupakan model regresi yang menghasilkan estimator linier tidak bias yang terbaik (Best Linier Unbias Estimator / BLUE). Kondisi ini akan terjadi jika dipenuhi beberapa asumsi yang disebut dengan Asumsi Klasik sebagai berikut :

1. Uji Normalitas

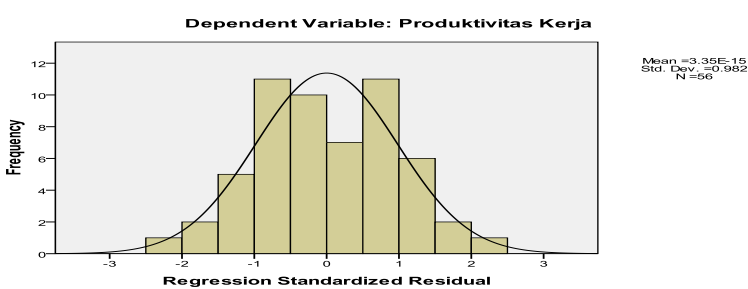

Gambar 3.1 Histogram

2. Uji Multikolinieritas

Tabel 3.1 Uji Multikolinieritas

Tabel Variance Infaltion Factor (VIF)

Coefficients $^{\mathrm{a}}$

\begin{tabular}{|c|c|c|c|c|c|c|c|}
\hline \multirow[b]{2}{*}{ Model } & \multicolumn{2}{|c|}{$\begin{array}{c}\text { Unstandardized } \\
\text { Coefficients }\end{array}$} & \multirow{2}{*}{\begin{tabular}{|c|}
$\begin{array}{c}\text { Standardized } \\
\text { Coefficients }\end{array}$ \\
Beta
\end{tabular}} & \multirow[b]{2}{*}{$\mathrm{t}$} & \multirow[b]{2}{*}{ Sig. } & \multicolumn{2}{|c|}{$\begin{array}{l}\text { Collinearity } \\
\text { Statistics }\end{array}$} \\
\hline & B & Std. Error & & & & Tolerance & VIF \\
\hline 1 (Constant) & -.808 & 3.033 & & -.267 & .791 & & \\
\hline Gaya Kepemimpin & .534 & .097 & .483 & 5.486 & .000 & .582 & 1.719 \\
\hline Penempatan & .525 & .097 & .478 & 5.423 & .000 & .582 & 1.719 \\
\hline
\end{tabular}

a. Dependent Variable: Produktivitas Kerja

Sumber: Data Primer yang telah diolah

Setelah melihat tabel diatas, maka dapat diketahui jika nilai VIF berada diantara nilai 1-10, hal ini menunjukan tidak terjadinya gejala Multikoinieritas artinya tidak adanya hubungan antar variabel bebas.

3. Uji Heterokedastisitas

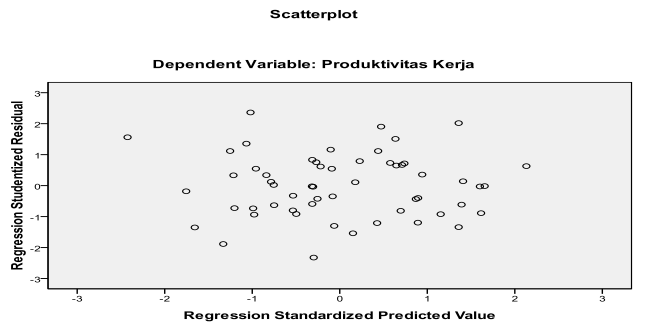

Gambar 3.2 Scatterplot 
Gambar diatas menunjukan titik-titik yang ada dalam grafik (Scatterplot) yang menyebar secara acak disekitar angka nol pada sumbu Y, maka dapat dipastikan unsur tidak mengandung gejala heterokedastisitas.

4. Uji Autokorelasi

Tabel 3.2 Durbin-Watson

Model Summary ${ }^{b}$

\begin{tabular}{|c|c|c|c|c|c|c|c|c|c|c|}
\hline \multirow[b]{2}{*}{ Model } & \multirow[b]{2}{*}{$\mathrm{R}$} & \multirow[b]{2}{*}{$\begin{array}{c}\mathrm{R} \\
\text { Square }\end{array}$} & \multirow[b]{2}{*}{$\begin{array}{c}\text { Adjusted R } \\
\text { Square }\end{array}$} & \multirow{2}{*}{$\begin{array}{l}\text { Std. Error } \\
\text { of the } \\
\text { Estimate }\end{array}$} & \multicolumn{5}{|c|}{ Change Statistics } & \multirow[b]{2}{*}{$\begin{array}{l}\text { Durbin- } \\
\text { Watson }\end{array}$} \\
\hline & & & & & $\begin{array}{l}\text { R Square } \\
\text { Change }\end{array}$ & $\begin{array}{c}\mathrm{F} \\
\text { Change }\end{array}$ & df1 & df2 & $\begin{array}{c}\text { Sig. F } \\
\text { Change }\end{array}$ & \\
\hline 1 & $.872^{\mathrm{a}}$ & .761 & .752 & 1.75069 & .761 & 84.199 & & 53 & .000 & 2.2 \\
\hline
\end{tabular}

a. Predictors: (Constant), Penempatan, Gaya kepemimpinan

b. Dependent Variable: Produktivitas Kerja

Dari hasil pengolahan data, dengan melihat tabel $\alpha=0,05$ dan $\mathrm{df}=\mathrm{n}-\mathrm{k}-1$ (56-2-1) dimana $\mathrm{k}$ adalah jumlah variable bebas, maka diketahui $\mathrm{dL}: 1,52$ dan $\mathrm{dU}: 1,59$, dan DW: 2,251 .

$4-\mathrm{dU} ; 4-1,59=2,41$

$4-\mathrm{dL} ; 4-1,52=2,48$

Dengan demikian nilai DW ada pada dU s.d 4-dU yang berarti "tidak ada Otokorelasi”

\section{B. Analisis Korelasi}

Data yang telah diintervalkan dengan program MSI (Metode of Successive Interval), selanjutnya dianalisis korelasi.

\section{Analisis Korelasi Parsial}

Untuk mengetahui keeratan hubungan antar variabel yang diteliti, peneliti menggunakan Korelasi Pearson Produck Moment. Teknik korelasi ini digunakan untuk mencari hubungan dan membuktikan hipotesis hubungan dua variabel bila data kedua variabel berbentuk interval atau rasio.

Interpretasi :

a. Nilai r sebesar 0,792 menunjukan bahwa terdapat hubungan yang sedang antara Gaya

Kepemimpinan dan Produktivitas yang berarti jika program Gaya Kepemimpinan dilaksanakan dengan tepat maka akan meningkatkan produktivitas kerja pegawai pada Dinas Koperasi dan UKM Kota Tangerang Selatan.

Sedangkan untuk mencari tingkat keberpangaruhan variabel gaya kepemimpinan terhadap produktivitas kerja pegawai maka digunakan Koefisien Determinasi sebagai berikut :

$\mathrm{Kd}=0,792^{2} \times 100 \%$

$=62,73 \%$

Angka Kd sebesar 62,73 \% menunjukan bahwa Variabel mempengaruhi Produktivitas Kerja pegawai sebesar 62,73 \% dan sisanya sebesar 37,27 \% dijelaskan oleh variabel lain diluar penelitian.

b. Nilai $r$ sebesar 0,790 menunjukan bahwa terdapat hubungan sedang dan positif antara Penepatan pegawai dan Produktivitas yang berarti jika penempatan pegawai dilakukan dengan tepat maka akan meningkatkan produktivitas kerja pegawai pada Dinas Koperasi dan UKM Kota Tangerang Selatan.

Sedangkan untuk mencari tingkat keberpangaruhan variabel Penempatan terhadap Produktivitas Kerja pegawai maka digunakan Koefisien Determinasi sebagai berikut : 
$\mathrm{Kd}=0,790^{2} \times 100 \%$

$=62,41 \%$

Angka Kd sebesar 62,59 \% menunjukan bahwa Variabel Penempatan Pegawai mempengaruhi Produktivitas Kerja sebesar 62,59 \% dan sisanya sebesar 37,59\% dijelaskan oleh variabel lain diluar penelitian.

\section{Analisis Korelasi Berganda}

Sedangkan Korelasi Ganda digunakan untuk mengetahui keeratan hubungan antar variabel jika variabel bebasnya lebih dari satu, adapun Analisis Korelasi Ganda dapat dilihat pada tabel berikut :

Tabel 3.3

Analisis Korelasi Ganda

Model Summary ${ }^{b}$

\begin{tabular}{|c|c|c|c|c|c|c|c|c|c|c|}
\hline \multirow[b]{2}{*}{ Model } & \multirow[b]{2}{*}{$\mathrm{R}$} & \multirow[b]{2}{*}{$\begin{array}{c}\mathrm{R} \\
\text { Square }\end{array}$} & \multirow[b]{2}{*}{$\begin{array}{l}\text { Adjusted } \\
\text { R Square }\end{array}$} & \multirow{2}{*}{$\begin{array}{c}\text { Std. } \\
\text { Error of } \\
\text { the } \\
\text { Estimate }\end{array}$} & \multicolumn{5}{|c|}{ Change Statistics } & \multirow[b]{2}{*}{$\begin{array}{l}\text { Durbin- } \\
\text { Watson }\end{array}$} \\
\hline & & & & & $\begin{array}{c}\text { R Square } \\
\text { Change }\end{array}$ & $\begin{array}{c}\mathrm{F} \\
\text { Change }\end{array}$ & df1 & df 2 & $\begin{array}{l}\text { Sig. F } \\
\text { Change }\end{array}$ & \\
\hline 1 & $.872^{\mathrm{a}}$ & .761 & .752 & 1.75069 & .761 & 84.199 & 2 & 53 & .000 & 2.251 \\
\hline
\end{tabular}

a. Predictors: (Constant), Penempatan, Gaya kepemimpinan

b. Dependent Variable: Produktivitas Kerja

Interpretasi :

a. Nilai R sebesar 0,872 menunjukan hubungan yang kuat dan positif antara variabel Gaya Kepemimpinan, Penempatan dan Produktivitas Kerja yang berarti jika Gaya Kepemimpinan dan penempatan pegawai dilaksanakan dengan tepat dan baik

b. Nilai R Square atau Koefisien Determinasi sebesar 0,752 menunjukan bahwa Variabel Gaya Kepemimpinan dan Penempatan pegawai mempengaruhi Produktivitas Kerja Pegawai sebesar $75 \%$ dan sisanya sebesar $25 \%$ dijelaskan oleh variabel lain diluar penelitian.

\section{Analisis Regresi Berganda}

Analisis Regresi Berganda digunakan untuk memprediksi niai variabel $Y$ (Produktivitas) jika variabel X1 (Gaya Kepemimpinan) dan X2 (Penempatan) dinaikan atau diturunkan. Hasil Adapun analisis Regresi berganda dapat dilihat pada tabel berikut

Tabel 3.4

Analisis Regresi Berganda

Coefficients $^{\mathrm{a}}$

\begin{tabular}{|c|c|c|c|c|c|c|}
\hline \multirow{2}{*}{\multicolumn{2}{|c|}{ Model }} & \multicolumn{2}{|c|}{$\begin{array}{c}\text { Unstandardized } \\
\text { Coefficients }\end{array}$} & \multirow{2}{*}{$\begin{array}{c}\begin{array}{c}\text { Standardized } \\
\text { Coefficients }\end{array} \\
\text { Beta }\end{array}$} & \multirow[b]{2}{*}{$\mathrm{t}$} & \multirow[b]{2}{*}{ Sig. } \\
\hline & & $\mathrm{B}$ & Std. Error & & & \\
\hline \multirow[t]{3}{*}{1} & (Constant) & -.808 & 3.033 & & -.267 & .791 \\
\hline & Gaya kepemimpinan & .534 & .097 & .483 & 5.486 & .000 \\
\hline & Penempatan & .525 & .097 & .478 & 5.423 & .000 \\
\hline
\end{tabular}

a. Dependent Variable: Produktivitas Kerja

Interpretasi :

1. Dari tabel diatas, maka dapat dibentuk persamaan sebagai berikut :

$\mathrm{Y}=-0,808+0,534 \mathrm{X} 1+0,525 \mathrm{X} 2$ 
2. Konstanta sebesar $-0,808$ menunjukan bila tidak ada peningkatan Gaya Kepemimpinan yang efektif dan Penempatan pegawai yang tepat maka nilai Produktivitas Pegawai adalah $-0,808$ atau berkurang sebesar 0,808.

3. Koefisien Regresi sebesar 0,534 menunjukan bahwa setiap peningkatan Gaya Kepemimpinan sebesar 1 maka akan meningkatkan Produktivitas Kerja sebesaar 0,534 .

4. Koefisien Regresi sebesar 0,525 menunjukan bahwa setiap peningkatan Penempatan Pegawai sebesar 1 maka akan meningkatkan Produktivitas Pegawai sebesaar 0,525.

\section{Pengujian Hipotesis}

\section{Uji Hipotesis I}

a. Kriteria pengujian hipotesis

Ho ; $\beta=0$, artinnya tidak ada hubungan antara Gaya Kepemimpinan terhadap Produktivitas kerja.

$\mathrm{Ha} ; \beta \neq 0$, terdapat hubungan antara Gaya Kepemimpinan terhadap produktivitas kerja.

b. Menentukan taraf nyata

Taraf nyata $(\alpha)$ yang digunakan adalah $5 \%$ atau 0,05

c. Kriteria pengambilan keputusan

Untuk menguji signifikasi apakah hipotesis yang ditetapkan semula diterima atau ditolak, dengan cara membandingkan antara $t$ hitung dengan $t$ table. Hasil yang didapatkan dari SPSS 16.0 memberikan t hitung untuk masing-masing variabel independen seperti table dibawah ini:

\section{Tabel 3.5}

Coefficients $^{\mathrm{a}}$

\begin{tabular}{|c|c|c|c|c|c|c|}
\hline \multirow{2}{*}{\multicolumn{2}{|c|}{ Model }} & \multicolumn{2}{|c|}{$\begin{array}{l}\text { Unstandardized } \\
\text { Coefficients }\end{array}$} & \multirow{2}{*}{$\begin{array}{c}\begin{array}{c}\text { Standardized } \\
\text { Coefficients }\end{array} \\
\text { Beta }\end{array}$} & \multirow[b]{2}{*}{$\mathrm{T}$} & \multirow[b]{2}{*}{ Sig. } \\
\hline & & B & Std. Error & & & \\
\hline \multirow[t]{3}{*}{1} & (Constant) & -.808 & 3.033 & & -.267 & .791 \\
\hline & Gaya kepemimpinan & .534 & .097 & .483 & 5.486 & .000 \\
\hline & Penempatan & .525 & .097 & .478 & 5.423 & .000 \\
\hline
\end{tabular}

Dengan melihat table distribusi t dengan $\alpha=5 \%$, df n-2 (56-2 =54) maka diperoleh $\mathrm{t}$ table $=2,004$ dan berdasarkan table diatas, secara parsial pengaruh gaya kepemimpinan (X1) terhadap produktivitas (Y) dalam uji t, didapat hasil t hitung sebesar 5,486 sedangkan $t$ tabel 2,004 dengan menggunakan taraf nyata sebesar 0,05. Karena t hitung 5,486 > t tabel 2,004, maka Ho = ditolat dan H1 = diterima, dengan demikian secara parsial gaya kepemimpinan ada hubungan secara signifikan terhadap produktivitas pegawai pada Dinas Koperasi dan UKM Kota Tangerang Selatan

\section{Uji Hipotesis II}

a. Kriteria pengujian hipotesis

Ho ; $\beta=0$, artinnya tidak ada hubungan antara Penempatan pegawai dengan Produktivitas kerja.

Ha $; \beta \neq 0$, terdapat hubungan antara Penempatan pegawai dengan produktivitas kerja.

b. Menentukan taraf nyata

Taraf nyata $(\alpha)$ yang digunakan adalah $5 \%$ atau 0,05 


\section{c. Kriteria pengambilan keputusan}

Untuk menguji signifikasi apakah hipotesis yang ditetapkan semula diterima atau ditolak, dengan cara membandingkan antara $\mathrm{t}$ hitung dengan $\mathrm{t}$ table. Hasil yang didapatkan dari SPSS 16.0 pada tabel 4.38 diatas.

Dengan melihat table distribusi t dengan $\alpha=5 \%$, df n-2 (56-2 =54) maka diperoleh $\mathrm{t}$ table $=2,004$ dan berdasarkan table diatas, secara parsial pengaruh penempatan (X2) terhadap produktivitas (Y) dalam uji t, didapat hasil $t$ hitung sebesar 5,423 sedangkan $t$ tabel 2,004 dengan menggunakan taraf nyata sebesar 0,05. Karena t hitung 5,423 $>\mathrm{t}$ tabel 2,004, maka $\mathrm{Ho}=$ ditolat dan $\mathrm{H} 1$ = diterima, dengan demikian secara parsial penempatan pegawai ada hubungan secara signifikan dengan produktivitas pegawai pada Dinas Koperasi dan UKM Kota Tangerang Selatan.

\section{Uji Hipotesis III}

Sedangkan untuk menguji hubungan Gaya Kepemimpinan dan Kesehatan dengan Produktivitas Pegawai, maka digunakan uji F dengan langkah-langkah sebagai berikut : a. Mencari F hitung

Untuk mengetahui angka F hitung maka dapat dengan melihat tabel Anova yang diperoleh melalui bantuan SPSS 16.0 berikut

Tabel 3.6

Anova (Analisys of Varians)

\begin{tabular}{|c|c|c|c|c|c|c|}
\hline \multicolumn{7}{|c|}{ ANOVA $^{b}$} \\
\hline \multicolumn{2}{|c|}{ Model } & $\begin{array}{l}\text { Sum of } \\
\text { Squares }\end{array}$ & Df & $\begin{array}{l}\text { Mean } \\
\text { Square }\end{array}$ & $\mathrm{F}$ & Sig. \\
\hline 1 & Regression & 516.126 & 2 & 258.063 & 84.199 & $.000^{\mathrm{a}}$ \\
\hline & Residual & 162.440 & 53 & 3.065 & & \\
\hline & Total & 678.566 & 55 & & & \\
\hline
\end{tabular}

a. Predictors: (Constant), Penempatan, Gaya kepemimpinan

b. Dependent Variable: Produktivitas Kerja

Dari tabel diatas maka dapat diketahui nilai F hitung $=84,199$

b. Mencari F tabel

Dengan melihat tabel Distribusi F dengan $\alpha=5 \%$, df n-k-1 (56-2-1 = 53) dimana $\mathrm{k}$ adalah jumlah variabel bebas; untuk uji dua pihak yaitu : 3,17

\section{PENUTUP}

Sebagai tahap akhir pembahasan dan analisis atas semua masalah yang telah diuraikan pada bab sebelumnya, maka pada bab ini penulis kemukakan kesimpulan dan saran-saran.

\section{A. Kesimpulan}

Berdasarkan hasil penelitian dan pembahasan maka penulis dapat menarik kesimpulan sebagai berikut :

1. Berdasarkan pengujian hipotesis, diperoleh nilai $t$ hitung $>t$ tabel $(5,486>2,004)$ maka Ho ditolak dan $\mathrm{H}_{1}$ diterima yang berarti terdapat hubungan yang signifikan antara gaya kepemimpinan dengan produktivitas kerja pegawai pada Dinas Koperasi dan UKM di Kota Tangerang Selatan.

2. Berdasarkan pengujian hipotesis, diperoleh nilai $t$ hitung $>\mathrm{t}$ tabel $(5,423>2,004)$ maka Ho ditolak dan $\mathrm{H}_{1}$ diterima yang berarti terdapat hubungan yang signifikan antara penempatan pegawai dengan produktivitas kerja pegawai pada Dinas Koperasi dan UKM di Kota Tangerang Selatan. 
3. Berdasarkan pengujian Hipotesis diperoleh nilai $F$ hitung $>F$ tabel $(84,199>3,17)$, maka Ho ditolak dan Ha diterima, yang berarti gaya kepemimpinan dan penempatan secara simultan mempunyai hubungan dengan signifikan terhadap produktivitas kerja pada Dinas Koperasi dan UKM di Kota Tangerang Selatan.

\section{B. Saran}

Dalam usaha meningkatkan produktivitas kerja pegawai pada Dinas Koperasi dan UKM Kota Tangerang Selatan. Adapun saran-saran yang penulis ajukan adalah sebagai berikut :

1. Bahwa pelaksanaan gaya kepemimpinan yang efektif adalah gaya kepemimpinan yang demokratis menunjukan pengaruh yang signifikan terhadap produktivitas pegawai, Sehingga dalam hal ini hubungan yang baik antara pimpinan dan pegawai dapat terjalin dengan baik yang akhirnya akan meningkatkan produktivitas kerja para pegawai Dinas Koperasi dan UKM Kota Tangerang Selatan.

2. Dinas Koperasi dan UKM Kota Tangerang Selatan harus dapat melakukan penempatan yang tepat sesuai dengan kemampuan, latar belakang pengalaman dan pendidikan yang dimiliki pegawainya, karena dengan penempatan yang tepat dapat meningkatkan rasa tangung jawab, disiplin dan kepuasan kerja yang pada akhirnya dapat meningkatkan produktivitas kerjanya.

3. Berdasarkan hasil analisa yang menunjukan korelasi yang positif, maka sudah seharusnyalah Dinas Koperasi dan UKM untuk meperbaiki terus menerus gaya kepemimpinan yang ideal untuk pegawainya dan penempatan pegawai yang tepat sesuai dengan pengalaman, pendidikan dan keterampilan yang tepat .

\section{DAFTAR PUSTAKA}

Budi Santoso, Purbayu. Analisis Statistik dengan Microsoft Excel \& SPSS, Yogyakarta: Andi. 2005

Handoko, T. Hani. Manajemen Personalia dan Sumber Daya Manusia, Yogyakarta: BPFE. 2001

Hasibuan, Malayu. Manajemen Sumber Daya Manusia, Edisi revisi Cetakan kelima. Jakarta: Bumi Aksara. 2002

Mangkunegara, Anwar Prabu. Manajemen Sumber Daya Manusia Perusahaan. Bandung: PT. Remaja Rosdakarya. 2004

Nawawi, Hadari. Manajemen Sumber Daya Manusia. Yogyakarta: Gajah Mada. 2003

P. Sondang, Siagian. Manajemen Sumber Daya Manusia. Jakarta: Mandar Maju. 2003

Panggabean, Mutiara S. Manajemen Sumber Daya Manusia, Jakarta: Bumi Aksara. 2004

Sedarmayanti. Sumber Daya Manusia dan Produktivitas Kerja, Edisi kedua. Bandung: Mandar Maju.2001

Sinungan, Muchdarsyah. Produktivitas Apa dan Bagaimana. Jakarta: Bumi Aksara. Cetakan Kelima. 2003

Sugiyono. Metode Penelitian Bisnis. Bandung: Alfabeta. 2004

Sunarsi, D. (2018). Pengaruh Rekrutmen, Seleksi Dan Pelatihan Terhadap Produktivitas Kerja Karyawan. Kreatif: Jurnal Ilmiah Prodi Manajemen Universitas Pamulang, 6(1), 14-31.

Peraturan Walikota Tangerang Selatan Nomor 01 tahun 2009 tentang Organisasi Perangkat Daerah Kota Tangerang Selatan

Umar, Husein. Riset Sumber Daya Manusia, Edisi Revisi cetakan keenam. Jakarta: PT. Gramedia Pustaka Utama. 2004

Undang-Undang Nomor 25 Tahun 1992 tentang Koperasi 